\title{
Trainer Kit Pengontrolan Motor Induksi Tiga Fasa dengan Sistem Monitoring Labview Di Laboratorium Teknik Mekatronika Politeknik Bosowa
}

\author{
Muhira Dzar Faraby ${ }^{1 *}$, Yoan Elviralita ${ }^{2}$, Andi Fitriati ${ }^{3}$, Iqbal Mansyur ${ }^{4}$, Kasma Amelia $^{5}$ \\ Teknik Mekatronika Politeknik Bosowa Makassar \\ Muhira_faraby@yahoo.com ${ }^{1}$, yoan.elviralita@yahoo.com², andi_fitriati@bosowa.co.id ${ }^{3}$, \\ iqbalmansyur@ymail.com ${ }^{4}$, kasmaamelia95@gmail.com ${ }^{5)}$
}

\begin{abstract}
The purpose of this final project is to design practical learning media for Electrical Machine Subject and also to understand the trainer kit performance by using LabVIEW monitoring system that applied in Mechatronic Laboratory of Bosowa Polytechnic. Some of models that can be assembled on this trainer kit as followed: direct online system, starting forward-reverse, two steps starting motor with resistance, manual and automatic three phase of induction motor control and generator induction.LabVIEW adjust relay switching using arduino. As a conclusion, the controlling of induction motor three phase with LabVIEW monitoring system work as the expected goal function of the experiment.
\end{abstract}

Keywords :Trainer Kit, Three-Phase Motor Induction, LabVIEW

\begin{abstract}
Abstrak
Tujuan dari pembuatan Tugas Akhir ini adalah untuk merancang media pembelajaran praktikum MesinMesin Listrik dan mengetahui unjuk kerja trainer kit pengontrolan motor induksi tiga fasa dengan sistem monitoring LabVIEW di Laboratorium Teknik Mekatronika Politeknik Bosowa. Beberapa model yang dapat dirangkai pada trainer kit ini yaitu sistem direct online (DOL), starting forward-reverse, starting dua langkah dengan menggunakan tahanan, kontrol motor induksi tiga fasa secara berurutan manual dan otomatis, kontrol motor induksi tiga fasa secara bergantian manual dan otomatis dan generator induksi. LabVIEW mengatur pemberian logika pensaklaran relay menggunakan arduino. Dapat disimpulkan bahwa pengontrolan motor induksi tiga fasa dengan sistem monitoring LabVIEW bekerja sesuai dengan tujuan percobaan yang akan dicapai.
\end{abstract}

Kata kunci :Trainer Kit, Motor Tiga Fasa, LabVIEW.

\section{Pendahuluan}

Proses pembelajaran merupakan tahapan-tahapan yang dilalui dalam mengembangkan kemampuan yang harus dimiliki oleh peserta didik. Politeknik Bosowa merupakan salah satu perguruan tinggi yang menyelenggarakan pendidikan vokasi untuk mempersiapkan tenaga ahli profesional dan keterampilan dibidangnya. Politeknik Bosowa dituntut agar mempunyai kelengkapan laboratorium dengan media pembelajaran dalam menunjang proses pembelajaran.

Pada Laboratorium Teknik Mekatronika Politeknik Bosowa, dibutuhkan media pembelajaran pengontrolan motor induksi tiga fasa dalam bentuk trainer kit yang disertai dengan modul panduan untuk memudahkan praktikan dalam menggunakan trainer kit tersebut. Penerapan trainer kit dapat mengondisikan kegiatan pembelajaran lebih terencana dengan baik, mandiri dan dengan hasil yang jelas.

Dari pertimbangan di atas, maka penulis bermaksud untuk membuat penelitian dengan judul Trainer Kit Pengontrolan Motor Induksi Tiga Fasa menggunakan LabVIEW. Trainer kit ini dilengkapi dengan modul [2] panduan penggunaan yang diharapkan dapat membantu proses pembelajaran MesinMesin Listrik, terhusus pada materi pengontrolan motor induksi tiga fasa [3]. Selain itu, trainer kit ini juga dilengkapi 
dengan LabVIEW [4] sebagai mode pengontrolan, sehingga proses pembelajaran akan menjadi lebih mudah.

\section{Metoda Penelitian}

Diagram blok rangkaian merupakan salah satu bagian terpenting dalam perancangan suatu alat, karena dari blok diagram rangkaian inilah dapat diketahui cara kerja rangkaian keseluruhan. Sehingga keseluruhan blog diagram rangkaian tersebut akan menghasilkan suatu sistem yang dapat difungsikan atau dapat bekerja sesuai dengan perancangan. Berikut blok diagram dari rangkaian sebagai berikut:

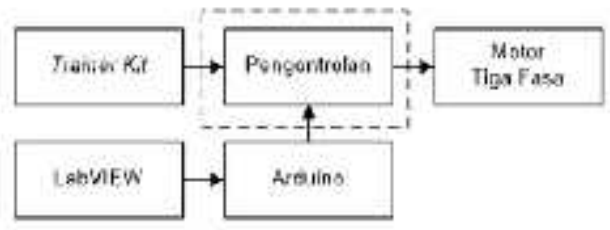

Gambar 1. Diagram Blok Rangkaian.

Berikut flowchart perencanaan dari trainer kit pengontrolan motor induksi tiga fasa menggunakan LabVIEW:

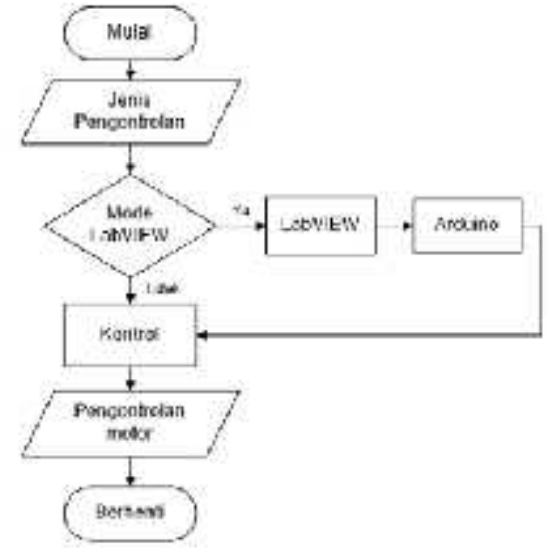

Gambar 2. Flowchart Perencanaan Sistem.

Dalam proyek ini, penulisan akan membahas bagaimana membuat sebuah trainer kit. Ini adalah sebuah trainer kit pengontrolan motor yang dilengkapi dengan pengontrolan mode LabVIEW menggunakan arduino [1]. Berikut gambar perancangan desain fisik dan layout trainer kit

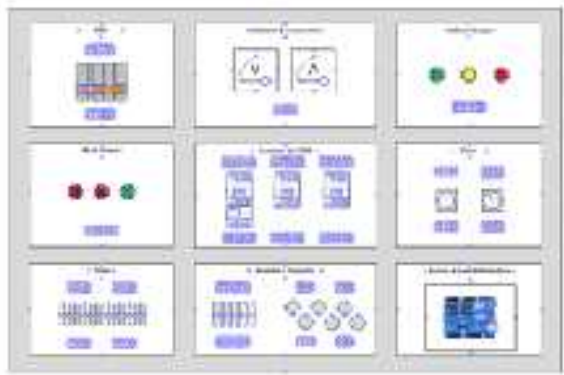

Gambar 3. Rancangan layout Trainer Kit.

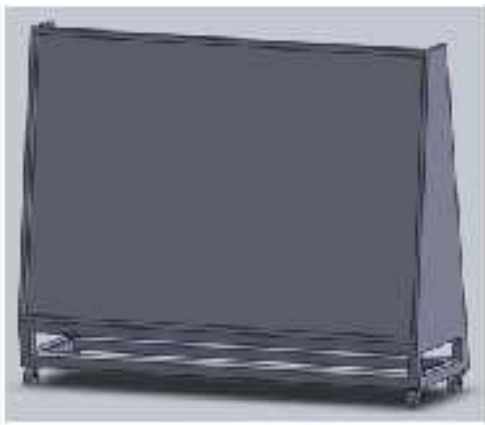

Gambar 4. Rancangan layout Trainer Kit.

\section{Hasil Penelitian}

\subsection{Hasil Karya Penelitian}

Berikut hasil rancang bangun trainer kit pengontrolan motor induksi tiga fasa.

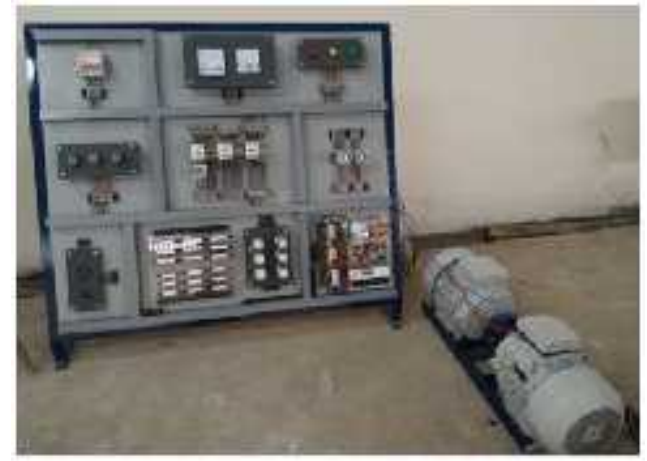

Gambar 5. Trainer Kit Pengontrolan Motor Induksi Tiga Fasa.

\subsection{Pengujiaan Kerja Rangkaian 3.2.1 Starting DOL (Direct Online)}

Ketika tombol start ditekan motor induksi tiga fasa mulai berputar dengan sistem DOL, dan ketika tombol stop ditekan, motor mulai berhenti berputar. Berikut Tabel 1. memuat hasil pengujian tegangan dan arus pada input motor: 
Tabel 1. Pengujian starting sistem Direct Online (DOL)

\begin{tabular}{|c|c|c|c|c|}
\hline \multirow{3}{*}{ rimil } & \multicolumn{3}{|c|}{ Kengukursn } & \multirow{3}{*}{ Kcontisi Molet } \\
\hline & Tugarikisn & \multicolumn{2}{|c|}{ Anux $\langle\mathrm{Ai}$} & \\
\hline & (V) & starting & Nominat & \\
\hline$R \cos$ & 383,3 & 17 & 3 & \multirow{3}{*}{$\begin{array}{l}\text { Burlyi pularan } \\
\text { moler halus } \\
\text { dan getjran } \\
\text { pada motor } \\
\text { rendah. }\end{array}$} \\
\hline (1) & $382, B$ & 17 & 3 & \\
\hline 5107 & 381,1 & $\psi$ & 3 & \\
\hline
\end{tabular}

\subsubsection{Starting Forward Reverse}

Berdasarkan hasil pengamatan yang dilakukan, dapat dilihat pada saat start $\mathrm{F}$ ditekan, maka coil $\mathrm{F}$ energized pada dan posisi push button OFF $\mathrm{R}$ akan menjadi deenergized. Sehingga, kontak-kontak $\mathrm{F}$ akan berubah keadaan yang mengakibatkan arus jala-jala tersuplai kemotor maka akan berputar searah jarum jam.

Sedangkan untuk keadaan reverse maka pada saat tombol start $\mathrm{R}$ ditekan maka coil $\mathrm{R}$ energized yang mengakibatkan perubahaan kontak dari F dan R. Sehingga, akan menyebabkan motor berputar berlawanan arah jarum jam. Hal tersebut dapat terjadi dengan adanya perubahan fasa R-S dan fasa S-R yang menyebabkan motor dapat berputar berlawanan arah dari putaran sebelumnya. Berikut Tabel 2. memuat hasil pengujian tegangan dan arus pada input motor:

Tabel 2. Pengujian starting forward-reverse

\begin{tabular}{|c|c|c|c|c|}
\hline \multirow{3}{*}{ Pdsë } & \multicolumn{3}{|c|}{ Penpi,ukur arn } & \multirow{3}{*}{ Kondisi Molor } \\
\hline & \multirow{2}{*}{$\begin{array}{c}\text { lojëngan } \\
\text { (vi) }\end{array}$} & \multicolumn{2}{|c|}{ Alus $(n)$} & \\
\hline & & Sroiting & Noninal & \\
\hline$\rho \operatorname{lis} S$ & 286,0 & 17 & . & $\begin{array}{l}\text { Munyi pulararı } \\
\text { motor nalıs dan }\end{array}$ \\
\hline & & & & $\begin{array}{l}\text { getarn poda } \\
\text { rnoler endah. }\end{array}$ \\
\hline$r$ to & 385,8 & 17 & 3 & $\begin{array}{l}\text { Saat reverse, } \\
\text { ghlattin incal:or }\end{array}$ \\
\hline$S$ to $T$ & 385,5 & $1 /$ & . & $\begin{array}{l}\text { pereintian arah } \\
\text { pularan molor. }\end{array}$ \\
\hline
\end{tabular}

\subsubsection{Starting Dua Langkah dengan Resistor}

Berdasarkan hasil pengamatan yang dilakukan, dapat dilihat pada saat start ditekan, maka coil $\mathrm{C} 1$ dan $\mathrm{S}$ akan merubah keadaan dari normally open memjadi normally close sehingga motor akan berputar lambat. Hal ini disebabkan dengan adanya resistor yang berfungsi untuk menghambat arus yang masuk kekumparan stator pada motor induksi.

Setelah time delay selesai mencacah, coil TD dan $\mathrm{C} 2$ akan $\mathrm{R}$ energized dan coil $\mathrm{C} 1$ de-energized yang mengakibatkan putaran motor akan semakin besar. Hal ini disebabkan karena tidak adanya resistor. Rangkaian starting dua langkah dengan tahanan ini berfungsi untuk mengurangi arus start yang masuk ke motor dengan tujuan untuk menjaga belitan motor. Berikut Tabel 3.memuat hasil pengujian tegangan dan arus pada input motor dengan menggunakan resistor 20W15RJ:

Tabel 3. Pengujian starting dua langkah dengan resistor

\begin{tabular}{|c|c|c|c|c|c|c|}
\hline \multirow{3}{*}{ I. नrgkali } & \multicolumn{5}{|c|}{ Penęi kuran } & \multirow{3}{*}{$\begin{array}{l}\text { Volior } \\
\text { Berputor }\end{array}$} \\
\hline & \multicolumn{3}{|c|}{ |r gағаг gan (V)] } & \multicolumn{2}{|c|}{ Mrus $\langle\Lambda\rangle$} & \\
\hline & $i \ln .5$ & Rinl & 5101 & Sorring & Neniriral & \\
\hline Lanzk:ah। & 0,005 & 0,005 & 0,005 & $c$ & 0 & $Y_{2}$ \\
\hline Longkah II & 405 & 403 & 403 & 13 & 3 & Tidak: \\
\hline
\end{tabular}

\subsubsection{Starting Berurutan}

Pengujian starting berurutan dilakukan dengan menggunakan dua buah motor, dimana kedua motor tersebut akan dirunning secara berurutan. Berikut Tabel 4 memuat hasil pengujian starting berurutan untuk motor pertama:

Tabel 4. Pengujian starting berurutan pada M-01

\begin{tabular}{|c|c|c|c|c|}
\hline \multirow{3}{*}{ Fäज } & \multicolumn{3}{|c|}{ Patkukutair } & \multirow{3}{*}{ Konstici Mrslen } \\
\hline & \multirow{2}{*}{$\begin{array}{c}\text { Toganean } \\
\text { (vi) }\end{array}$} & \multicolumn{2}{|c|}{$\operatorname{Rus}(\lambda)$} & \\
\hline & & storting & Nominal & \\
\hline$R \operatorname{los}$ & $586, \mathrm{C}$ & $i:$ & I & \multirow{3}{*}{$\begin{array}{l}\text { Ruinyi palaran } \\
\text { motror hallus } \\
\text { dan kelaran } \\
\text { parda mator } \\
\text { rerndati. }\end{array}$} \\
\hline n'tol & $58 \%, 8$ & 13 & $=$ & \\
\hline$s i c \mid$ & $s 8 s, 2$ & $1 ;$ & $=$ & \\
\hline
\end{tabular}

Setelah motor pertama running, motor kedua siap untuk di-running. Berikut Tabel 5 memuat hasil pengujian starting berurutan pada motor kedua. 
Tabel 5. Pengujian starting berurutan pada M-02

\begin{tabular}{|c|c|c|c|c|}
\hline \multirow{3}{*}{ Fitid } & \multicolumn{3}{|c|}{ Hengukuron } & \multirow{3}{*}{ Kunctisi Mostor } \\
\hline & \multirow{2}{*}{$\begin{array}{c}\text { Ti:gankan } \\
\langle(V)\end{array}$} & \multicolumn{2}{|c|}{ Arus $\{M]$} & \\
\hline & & Slis: insu & Nexrninial & \\
\hline ktos & $38 /, 0$ & 17 & 3 & \multirow{3}{*}{$\begin{array}{l}\text { Bunyi putaran } \\
\text { motor halus } \\
\text { d.m grlatiol } \\
\text { pada motor } \\
\text { rcridah. }\end{array}$} \\
\hline$\pi(1,5$ & 385,6 & $\%$ & . & \\
\hline 3201 & 385,0 & -1 & 3 & \\
\hline
\end{tabular}

\subsubsection{Starting Bergantian}

Pengujian starting bergantian dilakukan dengan menggunakan dua buah motor, dimana kedua motor tersebut akan dirunning secara bergantian. Berikut tabel 4.6 memuat hasil pengujian starting bergantian untuk motor pertama:

Tabel 6. Pengujian starting bergantian pada M-01

\begin{tabular}{|c|c|c|c|c|}
\hline \multirow{3}{*}{ רוה 1} & \multicolumn{3}{|c|}{ Pengukuran } & \multirow{3}{*}{ Kendisi Motor } \\
\hline & \multirow{2}{*}{$\begin{array}{c}\text { I =gangin } \\
(\mathrm{V})\end{array}$} & \multicolumn{2}{|c|}{ Arus $\langle A|$} & \\
\hline & & Starting & Maminal & \\
\hline $\mathrm{RS \textrm {ms }}$ & $38 / 7$ & 17 & 3 & lsunyi putaran \\
\hline$R \in D T$ & 386,6 & 1) & 3 & moter holus \\
\hline 5107 & 381.2 & 17 & 3 & $\begin{array}{l}\text { podi motor } \\
\text { rendah. }\end{array}$ \\
\hline
\end{tabular}

Setelah motor pertama running, motor kedua siap untuk di-running. Tabel 7 memuat hasil pengujian starting bergantian pada motor kedua.

Tabel 7. Pengujian starting bergantian pada M-02

\begin{tabular}{|c|c|c|c|c|}
\hline \multirow{3}{*}{ Fast } & \multicolumn{3}{|c|}{ Pengakuran } & \multirow{3}{*}{ Kuns:isi Mutolor } \\
\hline & \multirow{2}{*}{$\begin{array}{c}\text { Teparjan } \\
\text { |VI }\end{array}$} & \multicolumn{2}{|c|}{ Arasin) } & \\
\hline & & Slochling & Nomirnal & \\
\hline N to 5 & 386,6 & 11 & 3 & Bunpi putaran \\
\hline$R$ II $T$ & $.186,5$ & 17 & 3 & motor halus \\
\hline $5<01$ & 383,2 & $1 /$ & 3 & $\begin{array}{l}\text { phesal } 116 \mathrm{k}(\mathrm{s}) \\
\text { rendaht }\end{array}$ \\
\hline
\end{tabular}

\subsubsection{Pengujian Generator Induksi}

Pengujian dilakukan dengan menggunakan dua buah motor induksi yang dikopel dimana salah satunya bertindak sebagai generator induksi. Motor yang bertindak sebagai kopel dari generator menggunakan starting dengan sistem Direct Online (DOL). Output dari generator induksi dihubungkan dengan lamp indicator sebagai beban. Berikut Tabel 8 memuat hasil pengujian pada output generator:
Tabel 8. Pengujian generator induksi

\begin{tabular}{|c|c|c|c|}
\hline \multirow{2}{*}{ Fasa } & \multicolumn{2}{|c|}{ rengi kuran } & \multirow{2}{*}{$\begin{array}{c}\text { Rcndisi } \\
\text { Beban }\end{array}$} \\
\hline & 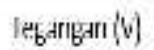 & Arus (nin) & \\
\hline $2+2 S$ & 12,31 & 1,74 & \multirow{3}{*}{$\begin{array}{l}\text { Nyli: } \\
\text { inoicotor } \\
\text { iunipg sctbaga } \\
\text { bebstra-tup }\end{array}$} \\
\hline ilis! & 1,31 & 1,9 & \\
\hline Sto $T$ & 12,31 & 1,74 & \\
\hline
\end{tabular}

\subsection{Pengujian Arduino dan LabView}

Pengujian interaksi Arduino dan LabVIEW berupa komunikasi serial menggunakan VISA terdiri atas dua bagian, yaitu, switchingrelay dan voltage and current monitoring. Berikut Tabel 9 menunjukkan hasil pengujian switching relay:

Tabel 9. Pengujian switching relay

\begin{tabular}{|c|c|c|c|}
\hline Beiay & Pin Input Arduino & Pir ICULN2804 & Kondisi \\
\hline Relay 1 & $D 2$ & $\ln 1$ & 3aik \\
\hline Feiay 2 & 33 & $\ln 2$ & toik: \\
\hline Rclay 3 & 0.4 & $\ln 3$ & saik \\
\hline Relay 4 & 0.5 & $\ln 4$ & Toik. \\
\hline Relay 5 & Dō & $\ln 5$ & Jaik. \\
\hline Reiay b & bl & $\ln 6$ & taik \\
\hline Ielay & DS & In/ & toik: \\
\hline Relay 8 & $D 9$ & $\ln 8$ & 3aik \\
\hline
\end{tabular}

Berdasarkan Tabel 9, terlihat hasil pengujian switching terhadap delapan buah Relay. Dapat dilihat bahwa Relay 1 diatur pengaktifannya melalui pin digital D2 Arduino yang terhubung ke pin input In1 IC ULN2804 yang selanjutnya akan mengalirkan arus ke coildan mengaktifkan Relay 1. Relay 2 diatur pengaktifannya melalui pin digital D3 Arduino yang terhubung ke pin input In2 IC ULN2804 yang selanjutnya akan mengalirkan arus ke coil dan mengaktifkan Relay 2. Relay 3 diatur pengaktifannya melalui pin digital D4 Arduino yang terhubung ke pin input In3 IC ULN2804 yang selanjutnya akan mengalirkan arus ke coildan mengaktifkan Relay 3. Begitulah seterusnya untuk Relay 4, Relay 5, Relay 6, Relay 7 dan Relay 8. Semua relay berfungsi dengan baik dimana pin normally open dan normally close dapat 
dimanfaatkan untuk mode pengaktifan pada rangkaian pengontrolan.

Pengujian kerja interaksi antara Arduino dan LabVIEW sebagai monitoring tegangan pada sistem pengontrolan motor dapat dilihat pada Tabel 10. berikut:

\begin{tabular}{|c|c|c|c|c|}
\hline \multicolumn{2}{|c|}{ Volbog: jensor } & \multirow{2}{*}{$\begin{array}{l}\text { Jelisih } \\
\text { betiaken } \\
\text { Input }\end{array}$} & \multicolumn{2}{|c|}{ Duspiay } \\
\hline reutiVAOI & Cutput IVDCI & & $\begin{array}{l}\text { Suibi } \\
\text { Aionitar }\end{array}$ & LabVIELW \\
\hline 0,52 & $1,-60$ & $C, 020$ & $21 \%$ & 211 \\
\hline 10 & $10 \leq C$ & 0,042 & 217 & 217 \\
\hline 20 & $1, c \leq_{2}$ & $\mathrm{C}, 047$ & 222 & 224 \\
\hline sn & $1,1: 9$ & $(0,052$ & 234 & $2: 4$ \\
\hline 10 & $1.19 \mathrm{C}$ & $c, 0 s 2$ & 215 & 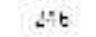 \\
\hline 30 & 1.43 & Cuss & $2 b 5$ & 203 \\
\hline 60 & $1.25 \mathrm{E}$ & 0,051 & 265 & 205 \\
\hline 70 & 1.349 & cos: & 273 & 279 \\
\hline 80 & 1.401 & $c, 054$ & $2 B C$ & 284 \\
\hline 90 & $11=5$ & C,USS & 295 & $2 \mathrm{gt}$ \\
\hline 100 & 1.500 & 0,001 & 302 & 303 \\
\hline 110 & 1.7\% & 0,077 & 112 & 714 \\
\hline 120 & $1, \equiv 4 E$ & $c, 006$ & 322 & 324 \\
\hline 130 & $1 \leq 22$ & $0,0 Z 2$ & 335 & sot \\
\hline 140 & 1574 & 0,008 & 343 & $3 \div 8$ \\
\hline 150 & 1,782 & c., nos & $\$ 55$ & 956 \\
\hline 160 & $1, \approx 87$ & 0,01 & 355 & $36 \epsilon$ \\
\hline 170 & $1, \equiv 97$ & 0,009 & 377 & $3 \pi$ \\
\hline 180 & 1706 & 0,005 & 385 & 385 \\
\hline 190 & 1.711 & r.mot & \$४5 & 395 \\
\hline$m a$ & 1,717 & $r, n a t$ & 4.25 & $49=$ \\
\hline 210 & $1, / 13$ & $\mathrm{v}, \mathrm{vOL}$ & 10s & rus \\
\hline 220 & 1715 & 0,003 & 412 & 412 \\
\hline 230 & 1.718 & $\mathrm{C}, 002$ & 425 & $4 i 5$ \\
\hline 240 & 1,720 & $\mathrm{c}, \mathrm{nn}_{4}$ & 425 & $4: F$ \\
\hline 250 & $1 / 121$ & - & $13 y$ & 105 \\
\hline
\end{tabular}

Berdasarkan Tabel 10 dapat diketahui hasil pengujian pada monitoring tegangan dengan menggunakan sensor tegangan. Sensor tegangan yang digunakan mampu mengukur tegangan listrik bolak-balik hingga $1000 \mathrm{~V}$. Pengujian dilakukan dengan pemberian tegangan input variabel mulai dari $0,453 \mathrm{~V}$ sampai 250V. Output dari sensor tegangan ini juga masih berupa tegangan listrik bolak-balik, sehingga diperlukan rangkaian pengkondisi sinyal untuk memperoleh output tegangan listrik searah. Untuk tegangan input sensor sebesar 0,453V AC sampai 250V AC, diperoleh output tegangan sebesar 1,030 V DC sampai $1,724 \mathrm{~V}$ DC yang selanjutnya akan diteruskan sebagai input ke Arduino.
Adapun nilai dari tegangan output sensor tegangan tersebut diperoleh dari pengaturan trimpot dari sensor tegangan itu sendiri sampai nilai minimum. Nilai output tersebut selanjutnya digunakan pada scaling. Diperoleh nilai selisih kenaikan tegangan sebesar 0,027VDC yang akan digunakan sebagai faktor pengali untuk setiap kenaikan 10VAC.

\section{Kesimpulan}

Trainer Kit Pengontrolan Motor Induksi Tiga Fasa dengan Sistem Monitoring LabVIEW dapat membantu proses pembelajaran praktikum mata kuliah mesinmesin listrik pada laboratorium Teknik Mekatronika Politeknik Bosowa menjadi lebih mudah.

Berdasarkan tahapan testing yang telah dilakukan, diketahui bahwa Pengontrolan Motor Induksi Tiga Fasa dengan Sistem Monitoring LabVIEW bekerja sesuai dengan tujuan percobaan yang akan dicapai sehingga layak digunakan pada Laboratorium prodi Teknik Mekatronika Politeknik Bosowa.

\section{Saran}

Perawatan trainer yang rutin sangat diperlukan hal ini bertujuan untukmenjaga usiatrainer supaya lebih awet, yakni dengan cara dilakukanpembersihan komponen sesaat sebelum dan setelah pelaksanaan praktikum.

Lakukan pengecekan komponen sebelum melakukan perakitan, hal inibertujuan agar apabila ada komponen yang rusak ataupun terlepas biasdilakukan perbaikan terlebih dahulu sebelum di rangkai.

Hindari menghidup-matikan MCB terlalu sering, sebab bila MBC terlalu sering hidup-mati usia MCB lebih cepat rusak. 
6. Daftar Pustaka

[1] Artanto, Dian.(2012).Interkasi Arduino dan LabVIEW (pp. 36-58), PT Elex Media. Jakarta.

[2] Ichwan Muhammad, Milda Gustiana Husaada, M. Iqbal.(2013).Pembangunnan Prototipe Sistem Pengendalian Peralatan Listrik pada Platform Android (ejurnal).Institut Teknologi Nasional, Bandung.

[3] Sirait, David H.(2008).Analisis Starting Motor Induksi Tiga Phasa pada PT. Berlian Unggas Sakti TJ. Morawa (e-jurnal). Universitas Sumatera Utara. Medan.

[4] Wardoyo, Siswo, Ri Munartu, Vicky Pratama Putra.(2013).Rancang Bangun Data Logger Suhu Menggunakan LabVIEW (e-jurnal). Universitas Sultan Ageng Tirtayasa, Cilegon Banten Indonesia. 